\title{
Onde está a Simetria? Uma investigação nos documentos oficiais e livros didáticos de Matemática
}

\author{
Josiane Aparecida Miranda Rafael \\ Especialista em Ensino de Matemática e Física \\ IF Sudeste MG - Campus Rio Pomba \\ josianeamr@gmail.com \\ Paula Reis de Miranda \\ Doutora em Educação Matemática \\ IF Sudeste MG - Campus Rio Pomba \\ paula.reis@ifsudestemg.edu.br
}

\section{Resumo}

Este estudo apresenta um recorte de uma pesquisa acerca da abordagem do conteúdo de Simetria em livros didáticos de matemática e em documentos educacionais com o objetivo de investigar e analisar as propostas para o ensino das simetrias nos anos finais do Ensino Fundamental contidas nas diretrizes curriculares nacionais, PCN, e do estado de Minas Gerais, CBC. Analisa-se também a abordagem desse conteúdo em duas coleções de livros didáticos distribuídas às escolas públicas brasileiras pelo Plano Nacional do Livro Didático (PNLD), no ano de 2017. A pesquisa é de natureza qualitativa, com técnica de análise documental e bibliográfica. Os resultados da investigação revelam que os documentos curriculares incentivam e orientam o ensino dos diferentes tipos de simetrias nos anos finais do Ensino Fundamental, bem como sua aplicação em diferentes contextos matemáticos. Entretanto, a análise didática mostra que nem todas as coleções didáticas aprovadas pelo PNLD 2017 e adotadas pelas escolas públicas brasileiras atendem inteiramente a estas propostas. A análise comparativa das duas coleções didáticas mostra que ambas trazem conteúdos de simetria no decorrer de seus volumes, com manipulações concretas, situações contextualizadas e interdisciplinares, porém com diferentes atividades, recursos didáticos e aprofundamentos. Observa-se que a coleção Vontade de Saber oferece maior suporte didático e pedagógico aos professores das escolas públicas, por melhor atender às diretrizes curriculares que norteiam o ensino público do país e do estado de Minas Gerais. Essas distinções na abordagem do tema simetria apontam para a importância da escolha do livro didático, de forma a atender as diretrizes curriculares propostas pelos documentos e a realidade de cada escola.

Palavras-chave: Ensino. Simetria. Livro didático. PCN. CBC.

Revista de investigação e divulgação em Educação Matemática, Juiz de Fora, v. 2, n. 1, p. 26-52, jan./jun. 2018. 


\title{
Where is the Symmetry? An investigation of official documents and mathematics textbooks
}

\begin{abstract}
This study presents a review of a research paper about the approach of Symmetry content in textbooks and educational documents. Its objective is to investigate and analyze the proposals for the teaching of symmetries in the final years of Elementary School contained in the national curricular guidelines and the guidelines from the state of Minas Gerais. Also analyzing the approach of this content in two collections of textbooks distributed to Brazilian public schools by the Textbook National Plan (PNLD), in the year 2017. The research is qualitative in nature, with documental and bibliographical analysis techniques. The results of the research show that although the curricular documents encourage and guide the teaching of the different types of symmetries in the final years of Elementary School, as well as their application in different mathematical contexts, not all didactic collections approved by PNLD 2017 and adopted by the brazilian public schools fully meet these proposals. The comparative analysis of the two didactic collections shows that both contain contents of symmetry throughout their volumes, with concrete manipulations, contextualized and interdisciplinary situations, but with different activities, didactic resources and deepening. It is noticed that the collection "Vontade de Saber" offers larger didactical and pedagogical supports to public school teachers, as they meet better the national curricular guidelines that serve as a north to the public school services in the country and in the state of Minas Gerais. These distinctions in the approach to the theme symmetry point to the importance of the choosing of the didactical book as a way to meet the curricular guidelines proposed in the documents and also the reality of each school.
\end{abstract}

Keywords: Teaching. Symmetry. Textbook. PCN. CBC. 


\section{Introdução}

Nos últimos anos, estudiosos têm salientado que o ensino da Geometria vem sendo abordado com menor intensidade na Educação Básica (PAVANELO, 1993; VELOSO, 2012, SENA e DORNELES, 2013). Oliveira (2016) nos convida a refletir sobre os possíveis fatores que possam contribuir para o abandono do ensino da Geometria nas salas de aula como, por exemplo, as dificuldades que muitos alunos enfrentam na aprendizagem desses conteúdos, bem como a falta de conhecimento do docente ao exercer sua profissão, decorrente de sua formação profissional.

Segundo Pavanelo (1993), o abandono da Geometria trata-se de um fenômeno mundial e, por isso, a autora convoca pensadores, profissionais da educação e matemáticos a atentarem para os possíveis impactos e prejuízos à formação lógica e matemática dos alunos, devido à ausência de uma disciplina que durante séculos fora considerada indispensável à formação intelectual dos indivíduos e ao desenvolvimento da capacidade de hábitos de raciocínio. Mesmo após duas décadas dos apontamentos feitos pela autora, as pesquisas de Sena e Dorneles (2013) reforçam que o estudo da Geometria não é uma das prioridades no ensino da Matemática, sendo que o descaso sobre o tema decorre do contexto histórico de seu ensino no Brasil e se faz presente no cotidiano atual.

Por fazer parte da Geometria, as transformações isométricas, comumente conhecidas por simetrias, podem ser, muitas vezes, deixadas de lado, visto que muitos professores se sentem inseguros em ensinar esse campo da Matemática, seja pela carência desses conteúdos (PAVANELO, 1993; SENA e DORNELES, 2013; OLIVEIRA, 2016) em sua formação docente ou até mesmo pelas dificuldades encontradas pelos alunos, uma vez que a deficiência no ensino da Geometria tem sua origem desde as séries iniciais da Educação Básica (CHIRÉIA, 2013). Pavanelo (1993) e Rezende (2015) destacam que a abordagem dos conteúdos de Geometria ao final do ano letivo, realizado por muitos professores, também favoreceu o seu abandono, mesmo que inconsciente, principalmente os de Simetria, pois devido ao currículo extenso, muitos não conseguem cumprir com o planejamento anual.

Embora sejam diversas as aplicações das simetrias, observa-se que esse conteúdo é abordado de maneira fragmentada, não permitindo ao aluno a ampla 
compreensão do conceito e, consequentemente, seu emprego em outras áreas do conhecimento. Aliás, observa-se que são poucos os livros didáticos do Ensino Fundamental e Médio que abordam o conceito de Simetria e, quando o fazem, o mesmo é tratado de maneira sucinta, com poucas definições ou propriedades, dando ênfase apenas à sua interpretação geométrica (CHIRÉIA, 2013).

Ao refletirmos sobre essa fragmentação não podemos esquecer que o conhecimento das diretrizes curriculares norteia o ensino da Matemática, em especial nas escolas públicas do país, ao mesmo tempo que sua observação na construção dos planejamentos curriculares, têm papel fundamental no exercício da prática docente em sala de aula e na formação intelectual do alunado.

De acordo com os Parâmetros Curriculares Nacionais, PCN (BRASIL, 1998), as diretrizes curriculares nacionais são referenciais tanto para a formação intelectual, social e cultural dos alunos, ao explicitar os conteúdos escolares que constituem a base de uma formação cidadã, como também podem orientar a produção de livros e materiais didáticos e nortear a formação inicial e continuada do profisssional docente, ao realçar, através dessas diretrizes, o tipo de profissional que se pretende formar (BRASIL, 1998).

Com o objetivo de fornecer uma base curricular comum à rede estadual de ensino em todo o estado de Minas Gerais, a Secretaria de Educação do Estado elaborou o Conteúdo Básico Comum (CBC), uma proposta curricular de caráter obrigatório, que visa estabelecer parâmetros que orientem a escola e professores na definição, organização, metodologia e avaliação dos conteúdos dos componentes curriculares das séries mencionadas, de maneira que sejam respeitadas as especificidades e identidade de cada escola.

Segundo o Guia Nacional do livro didático de Matemática para os anos finais do Ensino Fundamental, “[...], a grande maioria dos educadores atribui ao livro um papel de destaque entre os recursos que podem ser utilizados" (BRASIL, 2016, p. 13). Para Pires (2012), os livros didáticos são, sem dúvida, os materiais curriculares mais difundidos e utilizados no Brasil. Nesse tocante, torna-se importante investigar se os conteúdos matemáticos presentes nos livros didáticos, adotados pelas escolas públicas, atendem às diretrizes curriculares propostas pelas entidades governamentais competentes e se contribuem para a formação ampla e integrada do estudante.

O Plano Nacional do Livro Didático (PNLD) foi estabelecido por meio dos 
decretos $\mathrm{n}^{\mathrm{o}}$ 91.542, de 19 de agosto de 1985 (BRASIL, 1985) e $\mathrm{n}^{\circ} 7.084$ de 27 de janeiro de 2010 (BRASIL, 2010). Trata-se de "um programa de Estado que distribui às escolas públicas do Brasil, livros didáticos, dicionários e outros materiais de apoio à prática educativa, de forma sistemática, regular e gratuita” (BRASIL, 2016, p.5). Seu principal objetivo é fornecer subsídios à pratica pedagógica dos professores da educação básica das escolas públicas através da distribuição de material didático. Em ciclos trienais alternados, o Ministério da Educação (MEC), por meio do PNLD, avalia, divulga, adquire e distribui livros para todos os alunos de uma modalidade de ensino, que pode ser: anos iniciais do Ensino Fundamental, anos finais do Ensino Fundamental ou Ensino Médio.

O último ciclo do PNLD destinado aos anos finais do Ensino Fundamental, PNLD 2017, apresenta as coleções de Arte, Ciências da Natureza, Geografia, História, Língua Estrangeira Moderna, Língua Portuguesa e Matemática, que serão adotados no triênio 2017/2018/2019 pelas escolas públicas do Brasil. Só nesse ciclo, o PNLD distribuiu 152.351.763 exemplares para as séries do Ensino Fundamental e Médio das escolas públicas do país (BRASIL, 2017).

Com relação às coleções de livros de Matemática para os anos finais do Ensino Fundamental, o PNLD 2017 avaliou e aprovou 11 obras didáticas. O Guia Nacional do livro didático (BRASIL, 2016) traz a resenha crítica de cada coleção, disponibilizando aos professores uma síntese da avaliação da obra, destacando suas principais características no que se refere à abordagem dos conteúdos e à metodologia de ensino e aprendizagem, auxiliando-o no momento da escolha do livro didático a ser adotado pela escola.

A análise de conteúdos geométricos presentes nos livros didáticos adotados pelas instituições de ensino torna-se importante ao considerarmos o contexto histórico do ensino da Geometria no Brasil e o seu gradativo abandono no decorrer dos anos. No caso das transformações geométricas, entende-se que essa ação permitirá identificar quais conteúdos de Simetria têm sido priorizados pelos livros didáticos, qual a abordagem para o seu ensino (intuitiva ou dedutiva), bem como analisar o nível de abstração dos conceitos e suas aplicações.

Nesse sentido, a pesquisa justifica-se por se tratar de um dos poucos estudos que buscam analisar os conteúdos de Simetria propostos pelos livros didáticos dos anos 
finais do Ensino Fundamental, em consonância com as diretrizes curriculares que norteiam o ensino no país. Os estudos de Silva e Viana (2015) mostram que entre os anos de 2005 e 2015, foram realizados 16 estudos sobre a Geometria das transformações. Destas, apenas quatro são direcionadas aos anos finais do Ensino Fundamental, sendo o foco desses estudos, as aplicações em sala de aula com metodologia baseada na utilização de softwares matemáticos. Verificou-se que apenas um trabalho propõe a abordagem histórica sobre o ensino das transformações geométricas (LUZ, 2007), com base na análise de exercícios propostos em livros didáticos publicados, a partir dos anos 60, época na qual iniciava-se o Movimento da Matemática Moderna.

Sendo assim, o presente artigo tem por objetivo investigar e analisar as propostas para o ensino das simetrias nos anos finais do Ensino Fundamental contidas nas diretrizes curriculares nacionais, PCN, e no do estado de Minas Gerais, CBC. Busca-se também verificar se a abordagem desse conteúdo em duas coleções de livros didáticos distribuídas às escolas públicas brasileiras pelo Plano Nacional do Livro Didático (PNLD), no ano de 2017, correspondem ao que é proposto pelos documentos curriculares.

O texto apresentado é estruturado em seis tópicos. Na seção Introdução, são apresentadas as justificativas e os objetivos da pesquisa, bem como um breve contexto do ensino das simetrias nas escolas públicas brasileiras. Os materiais e métodos empregados durante o estudo são abordados na seção Procedimentos Metodológicos. O tópico Os PCN e o ensino das transformações geométricas, apresenta as diretrizes curriculares e orientações didáticas nacionais para o ensino das simetrias na rede pública. As orientações curriculares da Secretaria do Estado de Minas Gerais têm seu enfoque na seção Conteúdo Básico Comum e o ensino da Simetria. Na seção Sistematização crítica entre obras, CBC e PCN, é feita uma análise crítica entre os conteúdos de simetria presentes em duas obras didáticas de Matemática aprovadas no PNLD de 2017, adotadas a nível nacional, e as diretrizes curriculares propostas pelos documentos apreciados. Por último, apresentamos as Considerações Finais de nosso estudo. 


\section{Procedimentos Metodológicos}

A metodologia empregada consistiu em pesquisa bibliográfica e documental (SEVERINO, 2000), com análise das diretrizes curriculares propostas para o ensino da Simetria, em especial, o Conteúdo Básico Comum de Minas Gerais (MINAS GERAIS, 2007, 2014), documento que direciona o ensino na Educação Básica do estado de Minas Gerais, e os Parâmetros Curriculares Nacionais para os anos finais do Ensino Fundamental (BRASIL, 1998).

Após o levantamento dos conteúdos básicos de Simetria propostos para os anos finais do Ensino Fundamental, identificamos as obras didáticas de Matemática mais adotadas pelas escolas estaduais, primeiramente, em rede nacional e, posteriormente, em três escolas estaduais localizadas nas cidades de Piraúba, Tocantins e Rio Pomba. Para tal, foram consultados documentos, disponibilizados pelo Fundo Nacional de Desenvolvimento da Educação - FNDE (BRASIL, 2017), com dados estatísticos dos exemplares distribuídos nos ciclos do PNLD de 2017 para os anos finais do Ensino Fundamental.

Posteriormente, foram analisados registros de seleção de livros didáticos, disponibilizados nas bibliotecas de três escolas estaduais pesquisadas, denominadas nesse estudo como Escola 1, Escola 2 e Escola 3, das cidades de Piraúba, Tocantins e Rio Pomba, respectivamente. A partir dessas duas últimas análises documentais, foi possível selecionar as coleções de Matemática mais utilizadas pelas escolas, tanto em nível nacional como regional.

Sendo assim, foram selecionadas para análise didática dos conteúdos de Simetria as coleções: Praticando Matemática, de Andrini e Vasconcellos (2015), coleção mais adotada a nível nacional e por duas das três escolas investigadas, e a coleção Vontade de Saber, de Souza e Pataro (2015), segunda coleção mais distribuída às escolas públicas do país. No total, foram 8 livros didáticos de Matemática consultados e analisados. A análise dos conteúdos de Simetria presentes nos livros didáticos foi baseada na categorização de informações propostas por Fiorentini e Lorenzato (2012), como técnica de apreciação de dados qualitativos.

Ao final dessas análises, verificamos se as obras selecionadas e investigadas atendem às diretrizes curriculares propostas pela Secretaria de Educação do Estado de 
Minas Gerais, por meio do CBC, e pelo Ministério da Educação, por meio dos PCN, para o ensino da Simetria nos anos finais do Ensino Fundamental, apresentando uma tabela comparativa entre os conteúdos presentes nos documentos e aqueles encontrados nos livros didáticos pesquisados. Os resultados dessa investigação são apresentados nas seções a seguir.

\section{Os PCN e o ensino das transformações geométricas}

Criados em 1996 pelo Governo Federal, os PCN são referenciais curriculares que buscam nortear as equipes escolares na elaboração, desenvolvimento e execução de seus projetos pedagógicos, planejamento de aulas, seleção de recursos didáticos e tecnológicos, bem como promover uma reflexão sobre a prática pedagógica que contribua para a formação e atualização profissional. Os PCN foram elaborados com o intuito de fornecer aos jovens da nossa era, condições educacionais que permitam o acesso ao "conjunto de conhecimentos socialmente elaborados e reconhecidos como necessários ao exercício da cidadania para que deles possam usufruir” (BRASIL, 1998, p.49).

Seu objetivo principal é construir referências nacionais comuns ao processo educativo em todo Brasil, respeitando as diversidades regionais, culturais e políticas existentes no país. Em colaboração com os estados, distritos federais e municípios, o Governo Federal busca fornecer às escolas, diretrizes fundamentais que direcionem a estruturação e reestruturação dos currículos escolares e seus conteúdos mínimos, sendo obrigatórios para as escolas da rede pública e opcionais para as instituições privadas (BRASIL, 1998).

Com relação à área da Matemática, os PCN constituem um referencial para a construção de uma prática que favoreça o acesso ao conhecimento matemático, a fim de possibilitar aos alunos, a leitura, interpretação e compreensão do mundo ao seu redor, tornando-os capazes de interferirem e modificarem a realidade em que vivem, de desenvolverem suas capacidades cognitivas e sua confiança para enfrentar desafios, promovendo, assim, a inserção desses alunos no mundo do trabalho, nas relações sociais e da cultura (BRASIL, 1998). 
Para o terceiro ciclo do Ensino Fundamental ( $6^{\circ}$ e $7^{\circ}$ anos), no que tange às figuras geométricas, os PCN ressaltam a construção dos conceitos relacionados às transformações geométricas. Neste ciclo, os alunos devem ser estimulados a organizarem e ampliarem seus conhecimentos sobre Espaço e Forma, abordados no ciclo anterior, trabalhando problemas de localização no espaço e formas nele presentes, com um nível maior de complexidade e abstração. Em meio aos conteúdos propostos, deve-se enfatizar a exploração das figuras geométricas planas, pela sua decomposição e composição, transformação (reflexão, translação e rotação), ampliação e redução.

Dentre os conceitos e procedimentos de Espaço e Forma a serem trabalhados no terceiro ciclo do Ensino Fundamental, salientados pelos PCN, destacamos àqueles associados à Simetria:

Classificação de figuras tridimensionais e bidimensionais, segundo critérios diversos, como: corpos redondos e poliedros; poliedros regulares e não-regulares; prismas, pirâmides e outros poliedros; círculos, polígonos e outras figuras; número de lados dos polígonos; eixos de simetria de um polígono; paralelismo de lados, medidas de ângulos e de lados.

Transformação de uma figura no plano por meio de reflexões, translações e rotações e identificação de medidas que permanecem invariantes nessas transformações (medidas dos lados, dos ângulos, da superfície). (BRASIL, 1998, p. 73)

Os PCN ressaltam que as transformações geométricas podem parecer, à primeira vista, um assunto desconectado do cotidiano, sem relação com o nosso dia-a-dia, mas ao observarmos inúmeros objetos físicos, percebemos a aproximação de planos de simetria de reflexão, onde as representações planas desses objetos reduzem esses planos de simetria a eixos de simetria. Como exemplos, os PCN citam o corpo humano, a imagem de um objeto no espelho, bem como diversas criações do homem, como desenho de aeronaves, edifícios e móveis. Além disso, simetrias de todos os tipos também são incorporadas como linguagem básica nos programas de computação gráfica (BRASIL, 1998).

Também é possível identificar as simetrias centrais e de rotação em diversas situações como nos desenhos de flores, logotipos de empresas, bordados, copos, entre outros. Como exemplos de simetria de translação presentes no cotidiano, os PCN 
destacam as grades de janelas, cercas de jardins, frisos decorativos em paredes e azulejos decorados (BRASIL, 1998).

O Quadro 01 abaixo sistematiza os conteúdos, objetivos e orientações metodológicas propostos pelos PCN para o ensino das transformações isométricas, ou mais comumente conhecidas como simetrias, no $3^{\circ}$ ciclo do Ensino Fundamental.

Quadro 01 - Diretrizes Curriculares para o ensino da Simetria no $3^{\circ}$ ciclo do Ensino Fundamental

\begin{tabular}{|c|c|c|}
\hline \multicolumn{3}{|c|}{$3^{\circ}$ Ciclo $-6^{\circ}$ e $7^{\circ}$ Ano do Ensino Fundamental } \\
\hline Conteúdos de Simetria & Objetivos & Orientações metodológicas \\
\hline $\begin{array}{l}\text { Transformações isométricas } \\
\text { (reflexão, translação e } \\
\text { rotação) e identificação de } \\
\text { medidas que permanecem } \\
\text { invariantes r nessas } \\
\text { transformações (medidas dos } \\
\text { lados, dos ângulos, da } \\
\text { superfície). }\end{array}$ & $\begin{array}{l}\text { - Organizar e ampliar o } \\
\text { conhecimento dos alunos } \\
\text { sobre Espaço e Forma, com } \\
\text { um nível maior de } \\
\text { complexidade e abstração em } \\
\text { relação ao ciclo anterior; } \\
\text { - Permitir a construção dos } \\
\text { conceitos relacionados às } \\
\text { transformações geométricas. }\end{array}$ & $\begin{array}{l}\text { - Trabalhar problemas de localização } \\
\text { no espaço e formas nele presentes, } \\
\text { com um nível maior de } \\
\text { complexidade e abstração; } \\
\text { Identificar as simetrias centrais e de } \\
\text { rotação, translação e reflexão em } \\
\text { diversas situações, como nos } \\
\text { desenhos de flores, logotipos de } \\
\text { empresas, bordados, copos, entre } \\
\text { outros. }\end{array}$ \\
\hline $\begin{array}{l}\text { Eixos de simetria de um } \\
\text { polígono. }\end{array}$ & - & $\begin{array}{l}\text { - Trabalhar imagens do cotidiano, } \\
\text { imagem de um objeto no espelho, } \\
\text { entre outros. }\end{array}$ \\
\hline
\end{tabular}

Fonte: (BRASIL, 1998).

Sobre o desenvolvimento do pensamento geométrico no estudo das transformações no quarto ciclo ( $8^{\circ}$ e $9^{\circ}$ Ano), os PCN (1998) orientam a exploração de situações de aprendizagem que levem o aluno: (a) interpretar e representar a localização e o deslocamento de uma figura no plano cartesiano; (b) produzir e analisar transformações e ampliações/reduções de figuras geométricas planas, identificando seus elementos variantes e invariantes, desenvolvendo o conceito de congruência e semelhança. Os conceitos e procedimentos destacados pelos PCN para esse ciclo são:

Desenvolvimento do conceito de congruência de figuras planas a partir de transformações (reflexões em retas, translações, rotações e composições destas), identificando as medidas invariantes (dos lados, dos ângulos, da superfície). (BRASIL, 1998, p. 89)

Através da construção de figuras a partir da reflexão, da translação, da rotação de uma outra figura, os PCN (BRASIL, 1998) afirmam que os alunos irão perceber que as medidas dos ângulos e dos lados, da figura dada e da figura transformada são as 
mesmas. Segundo o documento, as atividades de transformação são fundamentais para que o aluno desenvolva habilidades de percepção espacial, além de favorecer a construção da noção de congruência de figuras planas (isometrias). Analogamente, o trabalho de ampliação e redução de figuras permite a construção da noção de semelhança de figuras planas (homotetias).

O quadro abaixo (Quadro 02) apresenta uma síntese dos conteúdos, objetivos e orientações metodológicas propostos pelos PCN para o ensino das transformações isométricas no $4^{\circ}$ ciclo do Ensino Fundamental.

Quadro 02 - Diretrizes Curriculares para o ensino da Simetria no $4^{\circ}$ ciclo do Ensino Fundamental

\begin{tabular}{|c|c|c|}
\hline \multicolumn{3}{|c|}{$4^{\circ}$ Ciclo $-8^{\circ}$ e $9^{\circ}$ Ano do Ensino Fundamental } \\
\hline Conteúdos de Simetria & Objetivos & Orientações metodológicas \\
\hline $\begin{array}{l}\text { - Transformações isométricas } \\
\text { no plano (reflexão ou } \\
\text { simetria axial, translação, } \\
\text { rotação, reflexão num ponto } \\
\text { ou simetria central, } \\
\text { identidade); } \\
\text { Desenvolvimento do } \\
\text { conceito de congruência de } \\
\text { figuras planas a partir de } \\
\text { transformações isométricas. }\end{array}$ & 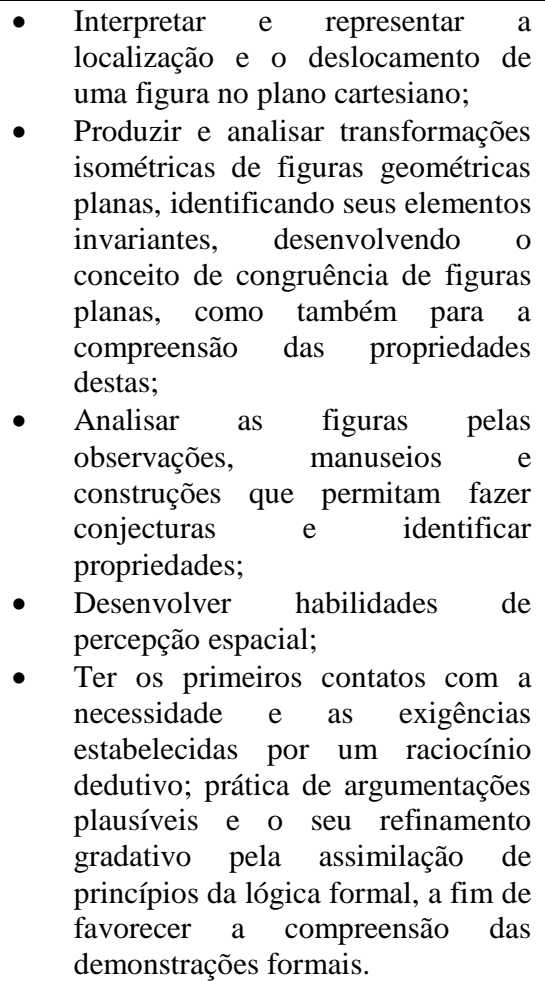 & $\begin{array}{l}\text { - Comparar duas figuras, em } \\
\text { que uma é resultante da } \\
\text { reflexão, translação ou } \\
\text { rotação da outra, como } \\
\text { também a descoberta das } \\
\text { medidas que permanecem } \\
\text { invariantes r nessas } \\
\text { transformações. } \\
\text { Desenvolver atividades } \\
\text { que permitam ao aluno } \\
\text { perceber que pela } \\
\text { composição } \\
\text { movimentos é possível } \\
\text { transformar uma figura em } \\
\text { uma outra. }\end{array}$ \\
\hline $\begin{array}{l}\text { - Construção de figuras a } \\
\text { partir da reflexão, por } \\
\text { translação, por rotação de } \\
\text { uma outra figura; } \\
\text { - Transformações de uma } \\
\text { figura no plano. }\end{array}$ & $\begin{array}{l}\text { - Levar o aluno a perceber que as } \\
\text { medidas dos lados e dos ângulos, da } \\
\text { figura dada e da figura transformada } \\
\text { são as mesmas; } \\
\text { Proporcionar um ambiente mais } \\
\text { dinâmico; } \\
\text { Permitir o desenvolvimento de } \\
\text { conceitos geométricos de uma } \\
\text { forma significativa. }\end{array}$ & 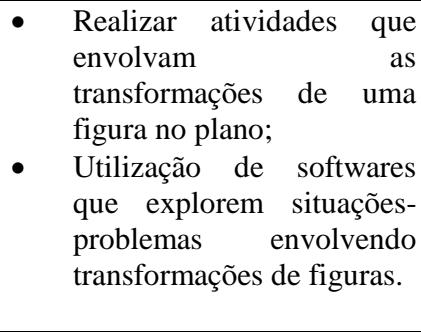 \\
\hline
\end{tabular}

Fonte: (BRASIL, 1998).

Revista de investigação e divulgação em Educação Matemática, Juiz de Fora, v. 2, n. 1, p. 26-52, jan./jun. 2018. 
Como pode ser observado no Quadro 02, nesse ciclo inicia-se o trabalho com algumas demonstrações. Nesse sentido, os PCN (BRASIL, 1998) apontam para o desenvolvimento do pensamento dedutivo, através de conteúdos, atividades e situações que possibilitem ao aluno os seus primeiros contatos com as exigências estabelecidas por um raciocínio dedutivo, a fim de permitir a construção de argumentos plausíveis, gradativamente aprimorados pela assimilação de princípios da lógica formal, possibilitando as demonstrações. Contudo, os PCN ressaltam que isso não significa priorizar um estudo absolutamente formal e axiomático, pois as verificações empíricas "permitem produzir conjecturas e ampliar o grau de compreensão dos conceitos envolvidos" (BRASIL, 1998, p. 87)

Como orientações didáticas tanto para o terceiro como para o quarto ciclo, os PCN (BRASIL, 1998) privilegiam atividades que envolvam as transformações de uma figura no plano, porque, além de proporcionar um ambiente mais dinâmico, elas permitem o desenvolvimento de conceitos geométricos de uma forma significativa. Nesse espaço de interação, os PCN salientam que também é possível a utilização de softwares que exploram situações-problemas envolvendo transformações de figuras.

Além disso, o professor pode propor aos alunos situações que permitam a comparação de duas figuras, em que uma é resultante da reflexão, translação ou rotação da outra, como também a descoberta das medidas que permanecem invariantes nessas transformações. Propõe-se também que esse estudo tenha, como ponto de partida, a observação de figuras do cotidiano, onde a simetria possa ser identificada, como as tapeçarias, vasos, cerâmicas, pisos, azulejos, entre outros.

No caso das transformações isométricas (transformações planas que conservam as medidas de comprimentos, ângulos e ordem de pontos alinhados), os PCN identificam seu estudo como um excelente ponto de partida para a construção e desenvolvimento das noções de congruência de figuras planas, como também para a compreensão das propriedades destas. As principais transformações isométricas são: reflexão ou simetria axial, translação, rotação, reflexão num ponto ou simetria central, identidade (BRASIL, 1998). Já as transformações que envolvem a ampliação ou redução de figuras (homotetias) servem de suporte para a construção e compreensão do conceito de semelhança de figuras.

No campo da Geometria, observa-se o incentivo de atividades e trabalhos que 
possibilitam o desenvolvimento de competências e habilidades que permitam ao aluno utilizar a Matemática na interpretação e intervenção da realidade, investigar e compreender problemas, formular hipóteses, prever resultados, distinguir e utilizar raciocínios dedutivos e indutivos, levantar e validar conjecturas, discutir ideias, produzir argumentos convincentes, entre outros.

Diante dos expostos, verifica-se que os PCN incentivam e orientam o estudo das transformações geométricas nos terceiro e quarto ciclos do Ensino Fundamental $\left(6^{\circ}\right.$ ao $9^{\circ}$ Ano). Entretanto, Oliveira (2016) destaca as dificuldades enfrentadas pelos professores ao lecionar esses conteúdos e as falhas no processo de formalização dos conceitos estudados pelos alunos, principalmente aqueles relacionados à geometria em movimento, isto é, às transformações geométricas (CHIRÉIA, 2013). Na próxima seção, investigaremos as diretrizes curriculares para o ensino da Simetria propostas pelo Conteúdo Básico Comum (CBC), documento que norteia o ensino das disciplinas nas escolas da rede pública de Minas Gerais.

\section{Conteúdo Básico Comum e o ensino da Simetria}

O Conteúdo Básico Comum (CBC) foi implantado nas escolas estaduais mineiras, em 2005, por meio da resolução $n^{\circ}$ 666, de 7 de abril de 2005 (MINAS GERAIS, 2005). Através do CBC, objetiva-se definir um conjunto de conteúdos básicos comuns a serem ensinados nos anos finais do Ensino Fundamental e Ensino Médio, inerentes ao processo de ensino e aprendizagem das diferentes áreas de estudo e à formação do cidadão crítico, reflexivo e ativo na sociedade. Além dos conteúdos básicos obrigatórios, o CBC também sugere conteúdos complementares e atividades (MINAS GERAIS, 2007). Nesse sentido, o CBC reforça que:

Estabelecer os conhecimentos, as habilidades e competências a serem adquiridos pelos alunos na educação básica, bem como as metas a serem alcançadas pelo professor a cada ano, é uma condição indispensável para o sucesso de todo sistema escolar que pretenda oferecer serviços educacionais de qualidade à população (MINAS GERAIS, 2007). 
Essa base curricular comum não dispõe de todos os conteúdos a serem abordados na escola, mas apresenta aspectos fundamentais de cada disciplina que não podem deixar de serem ensinados pelo professor e aprendidos pelos alunos. As escolas têm autonomia para definirem outros conteúdos, de acordo com projeto pedagógico estabelecido por elas. Além disso, o CBC é utilizado como matriz de referência para a elaboração de avaliações anuais do Programa de Avaliação da Rede Pública de Educação Básica (PROEB) e do Programa de Avaliação da Aprendizagem Escolar (PAAE), vinculado ao processo de Avaliação de Desempenho individual (ADI) dos docentes da rede estadual (MINAS GERAIS, 2007).

Diferente dos PCN, o CBC foi organizado em unidades estruturadoras, denominadas eixos temáticos, onde cada eixo é subdividido em temas e cada tema é sistematizado em tópicos que irão constituir o $\mathrm{CBC}$ para todas as propostas curriculares das Escolas Estaduais de Minas Gerais. Para cada tópico são apresentadas as habilidades a serem desenvolvidas pelos alunos durante seu estudo.

É válido ressaltar que o CBC de 2007 para os anos finais do Ensino Fundamental, não estava de acordo com as orientações trazidas pelos PCN (BRASIL,1998) sobre o ensino da Simetria. Seus conceitos eram de caráter complementar e, portanto, não havia obrigatoriedade em sua abordagem nas salas de aula. Além disso, nenhuma orientação pedagógica ou sugestão de atividades foi apresentada pelo documento para o ensino da Simetria nesse nível. A partir de 2014, com o documento revisado e atualizado, os conteúdos de Simetria passaram a ser obrigatórios e, além disso, são trazidas orientações pedagógicas para a condução do tema.

Os tópicos complementares e obrigatórios, bem como as orientações pedagógicas para o ensino da Simetria nos anos finais do Ensino Fundamental, apresentados pelo documento, foram estruturados no Quadro 03. 
Quadro 03 - Tópicos Obrigatórios e Complementares de Simetria nos anos finais do Ensino Fundamental $-6^{\circ}$ ao $9^{\circ}$ Ano - CBC 2014

\begin{tabular}{|c|c|c|c|c|c|c|}
\hline \multicolumn{7}{|c|}{ CBC $2014-6^{\circ}$ ao $9^{\circ}$ Ano } \\
\hline 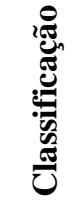 & $\underset{i}{i x}$ & & 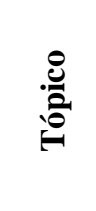 & ن & Habilidades & $\begin{array}{c}\text { Sugestão de } \\
\text { Atividades/Orientações } \\
\text { Pedagógicas }\end{array}$ \\
\hline \multirow{2}{*}{ 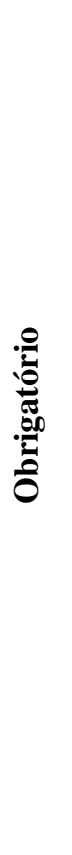 } & 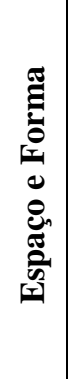 & 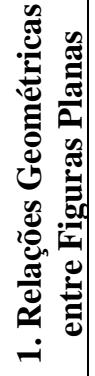 & 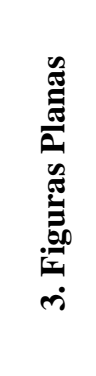 & 䜦 & $\begin{array}{l}3.4 \\
\text { Identificar } \\
\text { simetrias de } \\
\text { figuras em relação } \\
\text { a uma reta ou em } \\
\text { relação a um } \\
\text { ponto. }\end{array}$ & $\begin{array}{l}\text { - Sugestões de leituras; } \\
\text { - Utilização de papel transparente, } \\
\text { recortes ou, se possível, um } \\
\text { software de geometria dinâmica } \\
\text { como Cabri-Géomètre ou } \\
\text { GeoGebra ou ainda Tabula; } \\
\text { - Oficinas didáticas que explorem } \\
\text { a congruência de figuras. }\end{array}$ \\
\hline & 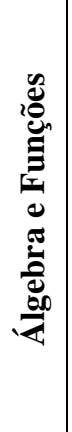 & 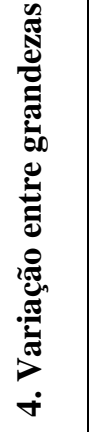 & 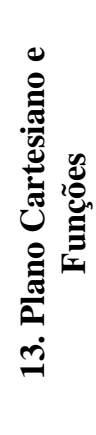 & 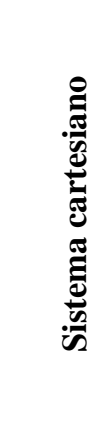 & $\begin{array}{c}13.2 \\
\text { Localizar pontos } \\
\text { no } \\
\text { plano cartesiano. }\end{array}$ & $\begin{array}{l}\text { - Após breve explanação sobre } \\
\text { simetria em relação aos eixos e à } \\
\text { origem, solicitar aos alunos que } \\
\text { marquem no plano cartesiano os } \\
\text { simétricos de pontos dados e, por } \\
\text { exemplo, o simétrico de um } \\
\text { segmento, identificando suas } \\
\text { extremidades. }\end{array}$ \\
\hline 晜 & 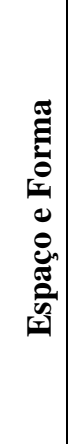 & 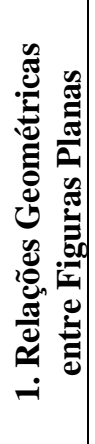 & 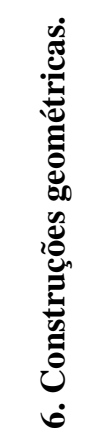 & 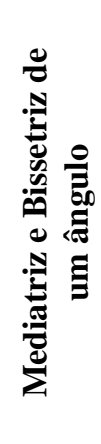 & \begin{tabular}{l}
\multicolumn{3}{c}{6.1} \\
Reconhecer \\
ponto médio de \\
um segmento, a \\
mediatriz de um \\
segmento, \\
bissetriz de um \\
ângulo com \\
figuras obtidas a \\
partir de \\
simetrias.
\end{tabular} & $\begin{array}{l}\text { - Construção da bissetriz de um } \\
\text { ângulo utilizando régua e } \\
\text { compasso; } \\
\text { - Utilização de software de } \\
\text { geometria dinâmica; } \\
\text { - Sugestões de leituras. }\end{array}$ \\
\hline
\end{tabular}

Fonte: (MINAS GERAIS, 2014).

Analisando o quadro acima, no Eixo Espaço e Forma, verifica-se que ensino das simetrias é apresentado como obrigatório nos anos finais do Ensino Fundamental. Esse conteúdo deve ser introduzido no $6^{\circ}$ Ano, aprofundado no $7^{\circ}$ e $8^{\circ}$ Ano e consolidado no $9^{\circ}$ Ano. Como orientações pedagógicas para o seu ensino, o CBC (MINAS GERAIS, 2014) sugere a leitura das obras Descobrindo padrões em mosaicos (BARBOSA, 1993)

Revista de investigação e divulgação em Educação Matemática, Juiz de Fora, v. 2, n. 1, p. 26-52, jan./jun. 2018. 
e Uma história da simetria na Matemática (Stewart, 2012). Segundo o documento, a abordagem dos conceitos de simetria deve ser intuitiva e informal, recorrendo-se a utilização de materiais concretos ou softwares de geometria dinâmica. Além disso, a partir desses conceitos, o professor poderá trabalhar noções de congruências entre figuras, principalmente os triângulos:

Esse estudo deve ter como objetivo desenvolver, intuitiva e informalmente os conceitos de reflexão, translação e rotação de figuras planas lançando mão de diferentes recursos como papel transparente, recortes ou, se possível, um software de geometria dinâmica como Cabri-Géomètre ou GeoGebra ou ainda Tabula de forma a permitir que o aluno identifique num conjunto de figuras, com ênfase nos triângulos, aquelas que coincidem por superposição. Sugerimos também a realização de oficinas didáticas que explorem a congruência de figuras. Após as atividades de superposição, o aluno já deve ser capaz de intuir que dois triângulos são congruentes se eles possuem todos os lados e todos os ângulos correspondentes congruentes. Esse é o momento para desafiar os alunos para o fato de que não é necessário conhecer a congruência dos três lados e dos três ângulos para concluir que os triângulos são congruentes. (MINAS GERAIS, 2014, p. 21-22)

O documento ainda sugere, como atividade, a construção de triângulos usando régua, compasso e transferidor ou um software quando possível - conhecidas as medidas de: a) seus três lados, b) dois lados e do ângulo compreendido entre eles e c) dois ângulos e o lado compreendido entre eles. Com essa atividade, além dos alunos verificarem a congruência dos diferentes triângulos construídos e suas propriedades, eles também poderão desenvolver habilidades de construção geométrica de triângulos com instrumentos de medição.

O tópico Construções Geométricas, do eixo Espaço e Forma, não é obrigatório, o mesmo propõe o conteúdo bissetriz de um ângulo com figuras obtidas a partir de simetrias. Contudo, as orientações trazidas para esse tópico referem-se a construções geométricas de pontos médios, mediatrizes, retas paralelas, retas perpendiculares e bissetriz, utilizando régua, compasso e softwares sempre que possível, mas nada mencionam sobre a utilização da Simetria como ponto de partida para o estudo da bissetriz de um ângulo. Acredita-se que o objetivo do $\mathrm{CBC}$ nessa habilidade seja reconhecer o eixo de simetria como a bissetriz de um ângulo em figuras simétricas. Para ampliar o conhecimento desse tópico, o CBC sugere as leituras: Aprendendo 
matemática com o Cabri Geométer II (NÓBREGA, 2003) e Construções geométricas: exercícios e soluções (NETTO, 2010).

No tópico Plano Cartesiano e Funções do eixo Álgebra e Funções, para o desenvolvimento da habilidade de localizar pontos no plano cartesiano, o CBC (MINAS GERAIS, 2014) orienta os professores a fazerem uma breve explanação dos conceitos de simetria de reflexão e central e, logo após, desenvolver atividades de localização de pontos simétricos a pontos dados, como também o simétrico de um segmento. De acordo com o documento em questão, esse tópico deve ser introduzido no $7^{\circ}$ Ano, aprofundado no $8^{\circ}$ Ano e consolidado no $9^{\circ}$ Ano.

Ao analisar os conceitos de Simetria presentes no CBC, observa-se que, em alguns casos, estes não são considerados conteúdos obrigatórios e, quando são, o tratamento dado a esse tópico é superficial, valorizando apenas o aspecto intuitivo e visual, não recorrendo às deduções formais, generalizações, definições ou propriedades. O CBC também não incentiva a construção de figuras simétricas, apenas a identificação destas, o que deixa a cargo do professor a responsabilidade pelo aprofundamento ou não do conteúdo e a metodologia a ser utilizada, o que pode contribuir, inconscientemente, para o adiamento do seu ensino para o final do ano letivo, ou até mesmo, para a exclusão desses conceitos dos planejamentos curriculares elaborados pelos professores.

Nesse tocante, entendendo o livro didático como um dos principais recursos que servirá de apoio ao professor em suas práticas em sala de aula e no desenvolvimento de metodologias que alcance os objetivos e habilidades propostos tanto pelos PCN (BRASIL, 1998) e CBC (MINAS GERAIS, 2014), vê-se a importância em identificar quais os conceitos de Simetria presentes nos livros didáticos, como é feita sua abordagem, qual o nível de abstração, quais sugestões de atividades e orientações pedagógicas.

O próximo tópico dessa seção, traz os resultados da seleção das obras didáticas a serem analisadas nessa pesquisa. 


\section{Sistematização crítica entre obras, CBC e PCN}

Esta seção apresenta os resultados da análise dos conteúdos de Simetria presentes nas coleções didáticas selecionadas, em observação às diretrizes curriculares propostas pelos PCN (BRASIL, 1998) e CBC (MINAS GERAIS, 2014) para o ensino de Simetria nos anos finais do Ensino Fundamental. Busca-se nessa seção, realizar uma análise do que tem sido proposto pelos documentos supracitados e o que tem sido abordado nos livros didáticos mais utilizados em rede nacional, no que diz respeito aos conteúdos de Simetria.

O Quadro 04, apresenta a relação dos conteúdos de Simetria presentes nos quatro volumes de cada coleção, de acordo com os conteúdos propostos pelos PCN (BRASIL, 1998). Os conteúdos foram distribuídos de acordo com os ciclos desse nível de ensino: $3^{\circ}$ ciclo $\left(6^{\circ}\right.$ e $7^{\circ}$ Ano) e $4^{\circ}$ ciclo ( $8^{\circ}$ e $9^{\circ}$ Ano).

Quadro 04 - Análise dos conteúdos/habilidades de Simetria presentes nas coleções, de acordo com os PCN

\begin{tabular}{|c|c|c|c|}
\hline \multicolumn{2}{|c|}{ CONTEÚDOS DOS PCN } & Praticando Matemática & Vontade de Saber \\
\hline \multirow{5}{*}{ 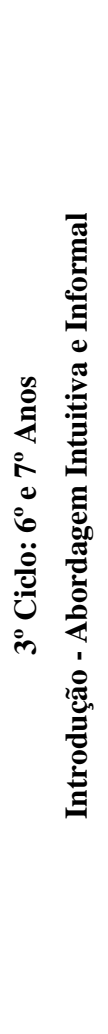 } & Simetria de Reflexão & - & $\begin{array}{l}\text { - Eixo de simetria e figuras } \\
\text { simétricas por reflexão - } 6^{\circ} \\
\text { e } 7^{\circ} \text { Ano. }\end{array}$ \\
\hline & Simetria de Rotação & - & $\begin{array}{l}\text {-Simetria de rotação, ângulo } \\
\text { de rotação e figuras } \\
\text { simétricas por rotação }-7^{\circ} \\
\text { Ano }\end{array}$ \\
\hline & $\begin{array}{l}\text { Simetria de } \\
\text { Translação }\end{array}$ & - & - \\
\hline & $\begin{array}{l}\text { Identificação de } \\
\text { medidas que } \\
\text { permanecem } \\
\text { invariantes nessas } \\
\text { transformações }\end{array}$ & - & - \\
\hline & $\begin{array}{l}\text { Eixos de Simetria de } \\
\text { um polígono }\end{array}$ & $\begin{array}{l}\text { - Eixo de simetria em } \\
\text { polígonos e círculo - } 6^{\circ} \text { e } 7^{\circ} \\
\text { Ano; } \\
\text { - Eixo de simetria para estudar } \\
\text { as propriedades relativas aos } \\
\text { ângulos dos triângulos } \\
\text { isósceles e equiláteros }-7^{\circ} \\
\text { Ano; } \\
\text { - Eixo de simetria como a } \\
\text { bissetriz do ângulo do vértice } \\
-7^{\circ} \text { Ano. }\end{array}$ & $\begin{array}{l}\text { - Eixo de simetria em } \\
\text { polígonos e círculos - } 7^{\circ} \\
\text { Ano. }\end{array}$ \\
\hline
\end{tabular}

Revista de investigação e divulgação em Educação Matemática, Juiz de Fora, v. 2, n. 1, p. 26-52, jan./jun. 2018. 


\begin{tabular}{|c|c|c|c|}
\hline \multirow{7}{*}{ 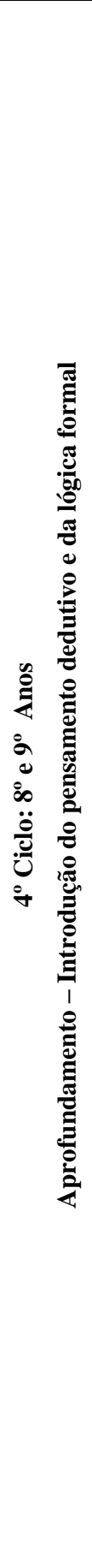 } & Simetria de Reflexão & $\begin{array}{l}\text { - Eixo de Simetria em figuras } \\
\text { planas, em triângulos, em } \\
\text { ângulos do vértice e em } \\
\text { propriedades das cevianas de } \\
\text { uma triângulo equilátero }-8^{\circ} \\
\text { Ano; } \\
\text { - Eixo de simetria em } \\
\text { Parábolas. }\end{array}$ & $\begin{array}{l}\text { - Pontos simétricos no plano } \\
\text { cartesiano }-8^{\circ} \text { Ano; } \\
\text { - Texto e exercícios sobre } \\
\text { eixo de simetria e pontos } \\
\text { simétricos em parábolas - } \\
9^{\circ} \text { Ano. }\end{array}$ \\
\hline & Simetria de Rotação & - & $\begin{array}{l}\text { - Rotação de uma figura, } \\
\text { ângulo e sentido de rotação } \\
\text { e simetria central } \\
\text { Ano). }\end{array}$ \\
\hline & $\begin{array}{l}\text { Simetria de } \\
\text { Translação }\end{array}$ & - & $\begin{array}{l}\text { - Translação de uma figura, } \\
\text { direção, sentido e distância } \\
\text { da figura transladada }\left(9^{\circ}\right. \\
\text { Ano). }\end{array}$ \\
\hline & $\begin{array}{c}\text { Simetria de Reflexão } \\
\text { num ponto ou simetria } \\
\text { central }\end{array}$ & - & - Simetria central $\left(9^{\circ}\right.$ Ano). \\
\hline & $\begin{array}{l}\text { Simetria de } \\
\text { Identidade }\end{array}$ & - & 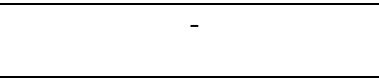 \\
\hline & $\begin{array}{c}\text { Transformações de } \\
\text { uma figura no plano: } \\
\text { construção de figuras } \\
\text { a partir da reflexão, } \\
\text { por translação e por } \\
\text { rotação de uma outra } \\
\text { figura. }\end{array}$ & - & $\begin{array}{l}\text { - } 6^{\circ} \text { Ano: construção da } \\
\text { simétrica de uma figura } \\
\text { por reflexão, com auxílio } \\
\text { de malha quadriculada e } \\
\text { software matemático; } \\
\text { - } 7^{\circ} \text { Ano: construção da } \\
\text { simétrica de uma figura } \\
\text { por reflexão e rotação, } \\
\text { utilizando malha } \\
\text { quadriculada e software } \\
\text { matemático; } \\
\text { - } 8^{\circ} \text { Ano: construção da } \\
\text { simétrica de uma figura } \\
\text { por reflexão no plano } \\
\text { cartesiano, por meio de } \\
\text { exercícios; } \\
\text { - e } 9^{\circ} \text { Ano: construção da } \\
\text { simétrica de uma figura } \\
\text { por rotação e translação, } \\
\text { utilizando malhas } \\
\text { quadriculadas, plano } \\
\text { cartesiano e software } \\
\text { matemático. }\end{array}$ \\
\hline & $\begin{array}{c}\text { Conceito de } \\
\text { congruência de figuras } \\
\text { planas a partir de } \\
\text { transformações } \\
\text { isométricas. }\end{array}$ & - & - \\
\hline
\end{tabular}

Fonte: Dados da pesquisa.

Observa-se que, dentre os conceitos de Simetria propostos pelos PCN para o terceiro ciclo: eixo de simetria em polígonos; transformações no plano (simetrias de reflexão, rotação, translação) e identificação de medidas que permanecem invariantes nessas transformações (medidas dos lados, dos ângulos, da superfície); dependendo da coleção, pouco ou quase nenhum dos conteúdos propostos pelo documento são abordados nos livros didáticos analisados.

Revista de investigação e divulgação em Educação Matemática, Juiz de Fora, v. 2, n. 1, p. 26-52, jan./jun. 2018. 
Por meio do Quadro 04, observa-se que a coleção Praticando Matemática, de Andrini e Vasconcellos (2015), aborda apenas o conteúdo eixo de simetria, tanto em polígonos e círculos, como em outros contextos matemáticos: estudo das propriedades dos triângulos, classificados quanto à medida dos lados; e bissetriz de um ângulo do vértice. Em nenhum momento, os autores definem ou fazem menção da simetria de reflexão, mas deixam esse conceito implícito nas atividades e exercícios propostos.

Já a coleção Vontade de Saber, de Souza e Pataro (2015), traz os conceitos: eixo de simetria, eixo de simetria nos polígonos e círculos, simetria de reflexão e simetria de rotação, sem associá-los a outros contextos matemáticos. Eixos de simetria e simetria de reflexão são abordados nos dois primeiros volumes da obra ( $6^{\circ}$ e $7^{\circ}$ Ano $)$, já a simetria de rotação é abordada a partir do $2^{\circ}$ volume.

Observa-se que as duas coleções analisadas trabalham a definição intuitiva e informal dos conceitos abordados, a partir de observações, visualização de figuras, contextos, manipulação concreta (recortes e dobraduras), seguida de atividades e exercícios. Apenas a coleção Vontade de Saber propõe atividades que permitem a construção de figuras simétricas tanto por reflexão, rotação ou translação, utilizando malhas quadriculadas, instrumentos de desenho e o software matemático GeoGebra.

Contudo, em nenhuma das coleções analisadas houve preocupação com o estudo das medidas que permanecem invariantes nessas transformações, como a medida dos lados, dos ângulos e da superfície das figuras. Os autores da coleção Vontade de Saber apenas deixam implícito que as figuras simétricas resultantes da reflexão ou da rotação de uma figura inicial, possuem a mesma forma e o mesmo tamanho.

Com relação aos conteúdos de Simetria do quarto ciclo dos anos finais do Ensino Fundamental, os PCN propõem a retomada dos conteúdos estudados no ciclo anterior, mas com intuito de possibilitar a introdução e o desenvolvimento do pensamento dedutivo, mantendo também as atividades experimentais e intuitivas. Também propõe-se o estudo das transformações isométricas no plano, a fim de favorecer a construção da noção de congruência de figuras planas (isometrias).

Analisando o Quadro 04, observa-se que a coleção Praticando Matemática, não traz nenhum dos conceitos propostos pelos PCN para o quarto ciclo dos anos finais do Ensino Fundamental. Apenas utiliza o conceito de eixo de simetria em figuras planas e em outros contextos matemáticos: propriedades dos triângulos, dos ângulos do vértice, propriedades das cevianas de um triângulo equilátero e na construção de gráficos da função quadrática.

A coleção Vontade de Saber, aborda no quarto ciclo as simetrias: de reflexão (por meio de textos e exercícios), rotação, translação e simetria central. Em todos os tipos de simetria 
estudados, os autores propõem a construção de figuras simétricas, seja com instrumentos de desenho, na malha quadriculada, no plano cartesiano ou utilizando o software matemático GeoGebra. Porém, por não estudarem as medidas que permanecem invariantes nessas transformações, as noções de congruências de figuras planas, a partir das simetrias, não são desenvolvidas em nenhum dos livros didáticos analisados.

Destaca-se que, em ambas as coleções, a abordagem dos conteúdos de Simetria é feita de maneira intuitiva e informal nos dois ciclos dos anos finais do Ensino Fundamental. Os autores propõem atividades investigativas e manipulativas que permitem verificar as propriedades e, até mesmo, abstração dos conceitos. Porém, estes não são apresentados na linguagem da matemática formal, nem há dedução lógica ou demonstrações.

No que tange aos conteúdos de Simetria propostos pelo CBC (MINAS GERAIS, 2014), observa-se que, de acordo com as séries, há uma sistematização dos conteúdos em etapas: alguns são introduzidos nos $6^{\circ}$ ou $7^{\circ}$ Anos, aprofundados nos $7^{\circ}$ ou $8^{\circ}$ Anos e consolidados no $9^{\circ}$ Ano. A abordagem destes, em todas as séries, deve ser intuitiva e informal, recorrendo-se a utilização de materiais concretos ou softwares de geometria dinâmica (MINAS GERAIS, 2014).

De acordo com o documento, nas turmas de $6^{\circ}$ e $7^{\circ}$ Ano, devem ser introduzidos conceitos de: simetrias em figuras planas em relação a uma reta (reflexão) ou em relação a um ponto (rotação e simetria central), localização de pontos simétricos no plano cartesiano e reconhecimento da bissetriz de um ângulo com figuras obtidas a partir de simetrias. Nas séries seguintes, propõe-se o aprofundamento e a consolidação desses conceitos

Com relação a coleção Praticando Matemática, observa-se que esta aborda, nas duas séries iniciais, apenas o conceito de eixo de simetria em figuras simétricas e, no $7^{\circ}$ Ano, trabalha o eixo de simetria como a bissetriz do ângulo do vértice de triângulos isósceles e equiláteros, conteúdo de caráter complementar do CBC. Não há identificação e nem definição dos tipos de simetrias em relação a uma reta ou a um ponto. Os conceitos de pontos e segmentos simétricos no plano cartesiano não são estudados nas séries iniciais da coleção, visto que plano cartesiano é abordado apenas no último volume da obra.

Quanto aos dois últimos volumes da coleção, não foi verificado a introdução, o aprofundamento e nem a consolidação dos conceitos propostos. № $9^{\circ}$ Ano, foi verificado uma abordagem sucinta de eixo de simetria e pontos simétricos da parábola em relação a esse eixo.

A coleção Vontade de Saber aborda a simetria de reflexão no $6^{\circ}$ Ano e retoma o seu estudo no $7^{\circ}$ Ano junto com a simetria de rotação. Porém, não estuda o eixo de simetria como a bissetriz do ângulo do vértice de figuras simétricas. Os conceitos de pontos e segmentos simétricos no plano cartesianos são apresentados no $8^{\circ}$ Ano, através de exercícios propostos. Nesse tópico, são estudados pontos simétricos com relação aos eixos ortogonais. No último 
volume da obra, as simetrias de reflexão e rotação voltam a ser estudadas e incluem-se a simetria de translação e simetria central. No estudo de gráficos de funções do $2^{\circ} \mathrm{Grau}$, os autores também abordam o eixo de simetria da parábola e trazem implícitas as noções de pontos simétricos da mesma.

Uma síntese dos conteúdos de Simetria presentes nas duas coleções analisadas, em consonância com as diretrizes curriculares propostas pelo CBC (MINAS GERAIS, 2014), são apresentados no Quadro 05.

Quadro 05 - Análise dos conteúdos/habilidades de Simetria presentes nas coleções, de acordo com o CBC

\begin{tabular}{|c|c|c|c|}
\hline \multicolumn{2}{|r|}{ Conteúdos/habilidades do CBC } & Praticando Matemática & Vontade de Saber \\
\hline \multirow{3}{*}{ 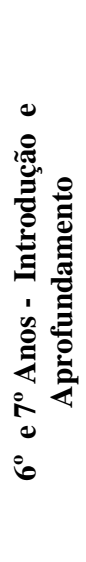 } & $\begin{array}{l}\text { Identificar simetrias de figuras em } \\
\text { relação a uma reta ou em relação a um } \\
\text { ponto (Introduzido no } 6^{\circ} \text { Ano e } \\
\text { Aprofundado no } 7^{\circ} \text { Ano). }\end{array}$ & $\begin{array}{l}\text { - Definição de eixo de simetria. } \\
\text { Não há explicações quanto à } \\
\text { classificação dos tipos de } \\
\text { simetrias. }\end{array}$ & $\begin{array}{l}\text { - Simetria de } \\
\text { reflexão e rotação. }\end{array}$ \\
\hline & $\begin{array}{l}\text { Marcar e localizar no plano cartesiano } \\
\text { os simétricos de pontos dados e, por } \\
\text { exemplo, o simétrico de um segmento, } \\
\text { identificando suas extremidades } \\
\text { (Introdução no } 7^{\circ} \text { Ano). }\end{array}$ & - & - \\
\hline & $\begin{array}{l}\text { Reconhecer a bissetriz de um ângulo } \\
\text { com figuras obtidas a } \\
\text { partir de simetrias (Complementar). }\end{array}$ & $\begin{array}{l}\text { - Definem a bissetriz de um } \\
\text { ângulo como o eixo de simetria } \\
\text { de uma figura. }\end{array}$ & - \\
\hline \multirow{2}{*}{ 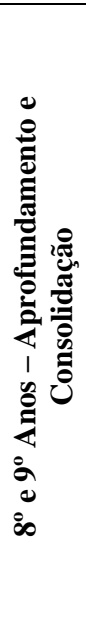 } & $\begin{array}{l}\text { Identificar simetrias de figuras em } \\
\text { relação a uma reta ou em relação a um } \\
\text { ponto (aprofundado no } 8^{\circ} \text { Ano e } \\
\text { Consolidado no } 9^{\circ} \text { Ano) }\end{array}$ & - & $\begin{array}{l}\text { - Reflexão (texto e } \\
\text { exercícios) - } 9^{\circ} \\
\text { Ano; } \\
\text { - Rotação } \\
\quad \text { (aprofundamento) } \\
\text {-9 Ano; } \\
\text { - Translação } \\
\text { (introdução) - } 9^{\circ} \\
\text { Ano. }\end{array}$ \\
\hline & $\begin{array}{l}\text { Marcar e localizar no plano cartesiano } \\
\text { os simétricos de pontos dados e, por } \\
\text { exemplo, o simétrico de um segmento, } \\
\text { identificando suas extremidades } \\
\text { (Aprofundado no } 8^{\circ} \text { Ano e Consolidado } \\
\text { no } 9^{\circ} \text { Ano). }\end{array}$ & $\begin{array}{l}\text { - Pontos simétricos em parábolas } \\
-9^{\circ} \text { Ano. }\end{array}$ & $\begin{array}{l}\text { - Exercícios de } \\
\text { pontos e figuras } \\
\text { simétricas no } \\
\text { plano cartesiano, } \\
8^{\circ} \text { e } 9^{\circ} \text { Ano; } \\
\text { - Pontos simétricos } \\
\text { em parábolas - } 9^{\circ} \\
\text { Ano. }\end{array}$ \\
\hline
\end{tabular}

Fonte: Dados da pesquisa.

Comparando as duas coleções, no que diz respeito aos conteúdos propostos pelo $\mathrm{CBC}$, observa-se, no Quadro 05, que a coleção Vontade de Saber possibilita um estudo mais amplo e aprofundado dos conteúdos de Simetria, por trazer abordagens, definições, atividades e exercícios dos diferentes tipos de simetria, bem como permite o desenvolvimento de noções de 
pontos e segmentos simétricos no plano cartesiano.

A coleção Praticando Matemática, embora utilize o conceito de eixo de simetria em contextos matemáticos de diferentes volumes: bissetriz de um ângulo ( $7^{\circ}$ Ano), propriedades dos triângulos ( $7^{\circ}$ e $8^{\circ}$ Ano) e gráficos de funções quadráticas ( $9^{\circ}$ Ano); vê-se que este é o único conceito de simetria abordado em toda a coleção. Até mesmo, a noção de pontos e segmentos simétricos são estudados apenas em relação ao eixo de simetria da parábola e, não, em relação aos eixos ortogonais.

Com relação à apresentação e abordagem dos conteúdos, as duas coleções apresentam a definição informal do conceito, a partir de manipulações concretas, atividades investigativas, resolução de exercícios, privilegiando, assim, o pensamento intuitivo. Nesse sentido, as obras Praticando Matemática e Vontade de Saber estão de acordo com o CBC, visto que o documento não propõe a abordagem dedutiva dos conceitos de Simetria. Porém, verifica-se que a coleção Vontade de Saber propiciou um maior número de atividades com recursos didáticos diversificados durante a abordagem dos conteúdos, inclusive atividades direcionadas com software de geometria dinâmica, GeoGebra, no estudo de todos os tipos de simetria.

Em geral, no tocante ao ensino das simetrias, observa-se que a coleção Vontade de Saber oferece maior suporte didático e pedagógico aos professores das escolas públicas, por melhor atender às diretrizes curriculares que norteiam o ensino público do país e do estado de Minas Gerais.

\section{Considerações Finais}

Apesar do abandono gradativo dos conteúdos de Simetria nos planejamentos escolares de Matemática, impulsionado, mesmo que de maneira inconsciente, pela Lei $n^{\circ}$ 5691/71 e pela abordagem estritamente formal proposta pelo Movimento da Matemática Moderna, a partir da década de sessenta, o estudo dos documentos que norteiam o ensino de Matemática nas escolas públicas do país nos dias atuais, PCN, e do estado de Minas Gerais, CBC, mostra que estes fornecem diretrizes curriculares que orientam e incentivam o ensino da Simetria nos anos finais do Ensino Fundamental.

Embora estes documentos apresentem suas especificidades e singularidades quanto a estruturação, abordagem, sugestões e orientações pedagógicas no tratamento do conteúdo, ambos são unânimes ao destacar a importância do estudo das transformações isométricas (reflexão, rotação e translação) no desenvolvimento da percepção espacial, noções relativas a posição, localização de figuras e deslocamentos no plano e sistemas de coordenadas. Incentivando também o seu estudo em outros contextos matemáticos como as Congruências de Revista de investigação e divulgação em Educação Matemática, Juiz de Fora, v. 2, n. 1, p. 26-52, jan./jun. 2018. 
figuras planas, Bissetrizes do ângulo do vértice, Plano cartesiano, entre outros.

Nosso trabalho nos permitiu concluir que, embora as obras didáticas investigadas abordem noções de Simetria no decorrer de todos os seus volumes, o tratamento dado a esse conteúdo difere de coleção para coleção. Verificou-se que a obra mais adotada pelas escolas públicas do país, e também em duas das escolas investigadas da região (Rio Pomba e Tocantins), Praticando Matemática, é a que menos aborda conceitos de Simetria, limitando-se apenas ao estudo de eixos de simetria em figuras simétricas e em outros contextos matemáticos. Por outro lado, a coleção Vontade de Saber, segunda obra mais adotada, traz os diferentes tipos de simetrias (reflexão, rotação e translação), atendendo melhor, a nosso ver, às diretrizes curriculares propostas nos documentos estudados e fornecendo maior suporte pedagógico aos professores no processo de ensino e aprendizagem do conteúdo.

Com relação à metodologia utilizada, observa-se que ambas as obras trazem atividades diversificadas que favorecem a aplicação, compreensão, contextualização e interdisciplinaridade dos conceitos; utilizam diferentes recursos didáticos e fornecem aos docentes o manual do professor, que orienta e auxilia na condução do trabalho em sala de aula.

A abordagem proposta pelos autores é adequada às séries da modalidade de ensino em estudo. Os autores utilizam de manipulações concretas, construções geométricas, visualização de figuras e esquemas ilustrativos, leitura de textos, recursos multimídias, entre outros. Apresentam a definição informal dos conceitos e oferecem aos professores diferentes situações de aprendizagem. Entretanto, não foi verificado situações que permitam ao aluno, experimentar, conjecturar, argumentar, levantar hipóteses, formalizar e generalizar conceitos de Simetria, tão pouco que possibilite as deduções e demonstrações. Desta forma, observa-se que as atividades propostas não favorecem o desenvolvimento do raciocínio formal e dedutivo para o último ciclo dos anos finais do Ensino Fundamental, o que não quer dizer que esse tipo de pensamento não esteja presente em outros tópicos matemáticos dos livros analisados.

As diferenças encontradas nas duas coleções, com relação aos conteúdos de Simetria, apontam para a importância da escolha do livro didático a ser utilizado pelas escolas durante os três anos de cada ciclo do PNLD. Os professores das escolas públicas, tendo conhecimento das diretrizes curriculares, tanto nacionais como estaduais (PCN e CBC), estão propensos a fazerem uma escolha acertada do livro didático, que o auxiliará na condução do seu trabalho docente em sala de aula, na aprendizagem dos conteúdos pelos alunos e no cumprimento do planejamento pedagógico curricular proposto em cada ano letivo. 


\section{Referências Bibliográficas}

BARBOSA, R. M. Descobrindo Padrões Em Mosaicos. São Paulo: Atual, 1993.

BRASIL, Ministério da Educação, Secretaria de Educação Fundamental. Parâmetros Curriculares Nacionais: Terceiro e quaro ciclos do Ensino Fundamental, Matemática. Brasília: MEC/SEF, 1998. 152 p.

Decreto n. 91.542, de 19 de agos. de 1985. Brasília, DF, agos. 1985.

Disponível em:

$<$ https://www.fnde.gov.br/fndelegis/action/UrlPublicasAction.php?acao=abrirAtoPublic o\&sgl_tipo $=D E C \& n u m \_a t o=00091542 \& s e q \_a t o=000 \& v l r \_a n o=1985 \& s g 1 \_o r g a o=N I \geq$. Acesso em: 23 de outubro de 2017.

Decreto n 7.084, de 27 de janeiro de 2010. Brasília, DF, jan. 2010.

Disponível em: <http://www.planalto.gov.br/ccivil_03/_ato2007-

2010/2010/decreto/d7084.htm>. Acesso em: 23 de outubro de 2017.

. MINISTÉRIO DA EDUCAÇÃO. Guia de Livros Didáticos PNLD 2016:

Matemática. Brasília: MEC, 2016.

. Ministério da Educação, Fundo Nacional de Desenvolvimento da

Educação. Dados Estatísticos: PNLD 2017. Disponível em: 〈http://www.fnde.gov.br〉. Acesso em: 05 de maio de 2017.

CHIRÉIA, J. V. Transformações Geométricas e a Simetria: Uma proposta para o Ensino Médio. 2013. 89 folhas. Dissertação apresentada ao Curso de Mestrado Profissional em Matemática em Rede Nacional - Universidade Estadual de Londrina, Londrina, 2013.

FIORENTINI, D.; LORENZATO, S. Investigação em educação matemática: percursos teóricos e metodológicos. $3^{\mathrm{a}}$ Ed. Campinas: Autores Associados, 2012.

LUZ, V. A. Um estudo sobre o Ensino de Transformações Geométricas: da reforma da Matemática Moderna aos dias atuais.2007.197f. Mestrado em Educação Matemática, Pontifícia Universidade Católica, São Paulo, 2007.

MINAS GERAIS, Governo do Estado. Currículo Básico Comum: Ensinos Fundamental e Médio. Belo Horizonte: Secretaria de Estado de Educação, 2007.

Currículo Básico Comum do Ensino Fundamental. Belo Horizonte: 
Secretaria de Estado de Educação, 2014.

Resolução SEE n. 666, de 07 de abril de 2005. Belo Horizonte:

Secretaria de Estado de Educação, abr, 2005. Disponível em:

$<$ https://www.educacao.mg.gov.br/images/documentos/\%7BA6FF8791-B1D3-4FBB-

B4B5-6AFEE169185A\%7D_resol0033.pdf >. Acesso em: 04 de novembro de 2017.

NETTO, S. L. Construções geométricas: exercícios e soluções. Rio de Janeiro: SBM, 2010 .

NÓBREGA, J. C. C.. Aprendendo matemática com o Cabri Geométer II. ABC-BSB, 2003.

OLIVEIRA, S. C. (Re)construção do pensamento geométrico de professores numa abordagem investigativa sobre simetria de reflexão. In: ENCONTRO NACIONAL DE EDUCAÇÃO MATEMÁTICA, 12., 2016. São Paulo. Anais... São Paulo: Universidade Cruzeiro do Sul, 2016. Online.

PAVANELLO, R. M. O abandono do ensino da geometria no Brasil: causas e consequências. In: Zetetiké: Campinas, ano 1, n.1, p. 7-17, 1993.

PIRES, C. M. C.; Grupo de Pesquisa: Desenvolvimento Curricular e Formação de Professores em Matemática. Texto base para a Organização do Projeto de Pesquisa sobre o Tema: Relações entre Professores e Materiais Que apresentam o currículo de Matemática: Um Campo Emergencial. São Paulo, 2012.

REZENDE, D. P. L. Ensino e aprendizagem de geometria: uma proposta para o estudo de polígonos nos anos finais do Ensino Fundamental. In: ENCONTRO BRASILEIRO DE ESTUDANTES DE PÓS-GRADUAÇÃO EM EDUCAÇÃO MATEMÁTICA. XIX. 2015. Juiz de Fora. Anais... Minas Gerais. Universidade Federal de Juiz de Fora, 2015. Online.

SENA, R. M.; DORNELES, B. V. Ensino de Geometria: Rumos da Pesquisa (19912011). In: Revemat: Florianópolis (SC), v. 08, n. 1, p. 138-155, 2013.

SEVERINO, A. J. Metodologia do Trabalho Científico. 21 ed. São Paulo: Cortez, 2000.

SILVA, P; VIANA M. História da Educação Matemática e Geometria das Transformações: Um estudo sobre as produções brasileiras atuais. In: ENCONTRO MINEIRO DE EDUCAÇÃO MATEMÁTICA, 7., 2015. Juiz de Fora. Anais... Minas 
Gerais: Universidade Federal de Juiz de Fora, 2015. Online.

SOUZA, J. R. de; PATARO, Patricia Rosana Moreno. Vontade de Saber Matemática. 3. ed. São Paulo: FTD, 2015. Coleção Vontade de Saber Matemática ( $6^{\circ}$ ao $9^{\circ}$ ano).

STEWART, I. Uma história da simetria na matemática. 1.ed. Tradução de Claudio Carina. Rio de Janeiro: Zahar, 2012.

VELOSO, E. Simetria e transformações geométricas. Lisboa: Associação de Professores de Matemática - APM, 2012.

Recebido em: 05 de março de 2018. Aprovado em: 22 de maio de 2018. 